\title{
Trivium
}

Revue franco-allemande de sciences humaines et sociales - Deutsch-französische Zeitschrift für Geistesund Sozialwissenschaften

$3 \mid 2009$

Droits subjectifs et droits de l'homme

\section{Für eine Politik der subjektiven Rechte: der Kampf um Rechte als politischer Kampf}

\section{Catherine Colliot-Thélène}

Traducteur : Bernd Schwibs

\section{(2) OpenEdition}

Journals

Édition électronique

URL : http://journals.openedition.org/trivium/3316

DOI : $10.4000 /$ trivium.3316

ISSN : 1963-1820

Éditeur

Les éditions de la Maison des sciences de l'Homme

Référence électronique

Catherine Colliot-Thélène, «Für eine Politik der subjektiven Rechte: der Kampf um Rechte als politischer Kampf », Trivium [En ligne], 3 | 2009, mis en ligne le 15 avril 2009, consulté le 07 septembre 2020. URL : http://journals.openedition.org/trivium/3316 ; DOI : https://doi.org/10.4000/trivium.3316

Ce document a été généré automatiquement le 7 septembre 2020.

\section{cc)}

Les contenus des la revue Trivium sont mis à disposition selon les termes de la Licence Creative Commons Attribution - Pas d'Utilisation Commerciale - Pas de Modification 4.0 International. 


\title{
Für eine Politik der subjektiven Rechte: der Kampf um Rechte als politischer Kampf
}

\author{
Catherine Colliot-Thélène
}

Traduction : Bernd Schwibs

\section{NOTE DE L'ÉDITEUR}

Wir danken der Zeitschrift L'année sociologique und den Presses Universitaires de France für die freundliche Genehmigung, diesen Artikel zu übersetzen.

1 Seit ungefähr zwei Jahrzehnten wird die Aushöhlung der staatlichen Souveränität von Politikwissenschaftlern ebenso wie von Soziologen und Juristen breit kommentiert. ${ }^{1}$ Die politische Philosophie dagegen zögert, sich über die Implikationen im Hinblick auf sie selbst Gedanken zu machen. In ihrer modernen Gestalt, die sich aus den Vertragstheorien des 16. und 17. Jahrhunderts entwickelte, gilt ihr als ausgemacht, dass der Staat die moderne Ausprägung des politischen Gemeinwesens darstellt und dementsprechend den Rahmen bildet, innerhalb dessen die ihm traditionell zustehenden Fragen zu behandeln sind: Rechtspflege, öffentliche Wohlfahrt und die Voraussetzungen der Legitimität der Macht. Die zeitgenössischen Debatten zwischen Liberalen, Kommunitaristen und Republikanern stellen diesen Rahmen nicht in Frage; zaghafte Ausblicke auf internationale oder kosmopolitische Perspektiven oder auch die gegenwärtig brennende Frage nach dem Status von Ausländern werden entweder am Rande thematisiert ${ }^{2}$ oder auf der Grundlage einer möglichen Neudefinition der Voraussetzungen von Staatsbürgerschaft reflektiert, die gleichwohl etatistisch, d.h. nationalstaatlich, bleibt. ${ }^{3}$ Auch wenn eine umfängliche Literatur heute die Schwäche dieser ausschließlich nationalstaatlichen Konzeption von Staatsbürgerschaft dokumentiert, scheinen die Philosophen die Furcht zu hegen, mit ihrer Aufgabe auch des vertrauten Bodens verlustig zu gehen, auf dem sie sich zu orientieren wissen, und dann in unbekanntem Gelände ohne Kompass herumirren zu müssen. Eines der Ziele 
der folgenden Seiten besteht darin, sie einzuladen, diese Hemmung zu überwinden. Die moderne Philosophie ist unzweifelhaft eine Philosophie des souveränen Staats gewesen; sie gibt uns jedoch Mittel an die Hand, die Voraussetzungen der Politik nach dem Ende des staatlichen Machtmonopols zu denken. Dazu müssen die Philosophen allerdings eine Neulektüre ihrer Tradition vornehmen. Auf deren Grundlage soll hier nur verwiesen werden: Es geht darum, das vergessene Bündnis zwischen politischer Philosophie und Rechtsphilosophie neu zu knüpfen (1.).

Unter dieser Voraussetzung sind die Philosophen in der Lage, einen nicht unerheblichen Beitrag für all jene Disziplinen zu leisten, die die zeitgenössischen Wandlungsprozesse in Gesellschaft, Politik und Recht reflektieren. Im Folgenden wird der Rechtssoziologie (vertreten durch Max Weber) und der Rechtstheorie besondere Aufmerksamkeit gewidmet. Schnittpunkt aller Texte, auf die wir uns stützen, ist der Begriff des "subjektiven Rechts«. Gegen den Verruf, in den dieser Begriff bei den meisten Juristen und bei bestimmten Philosophen geraten ist ${ }^{4}$, wird hier die These vertreten, dass das Rechtssubjekt die moderne Figur des politischen Subjekts darstellt: eines Subjekts, dem nichts Natürliches eignet, das sich vielmehr in der historischen Entwicklung der modernen liberalen Demokratien herausgebildet hat (2.). Erlaubt die Neulektüre des Korpus der modernen politischen Philosophie eine Rehabilitierung der Figur des Rechtssubjekts, mit der sie ins Zentrum unseres Verständnisses der modernen Demokratie rückt, so wird der Umweg über die soziologischen und juristischen Debatten um den Begriff der subjektiven Rechte uns andererseits ermöglichen, die Voraussetzungen für einen strikten Umgang mit dieser Denkfigur zu benennen. Streng genommen gibt es Rechte nur unter der Voraussetzung ihrer Gewährleistung durch eine Machtinstanz (3.). Diese Machtinstanz war früher der Staat als der exklusive Gesprächspartner des Rechte einklagenden Subjekts. Mit der Aushöhlung der staatlichen Souveränität, die zum Teil zurückgeht auf die freiwillige Übertragung nationalstaatlicher Befugnisse auf übernationale Instanzen, aber auch auf das Entstehen neuer polymorpher Machtinstanzen, die rechtliche oder quasi-rechtliche Regulierungen autonom hervorbringen, wird diesem exklusiven Status ein Ende bereitet. Das ungewisse Geschick des politischen Subjekts entscheidet sich fortan in dem durch diese neuen Machtinstanzen gebildeten hierarchielosen Raum (4.).

\section{Die moderne politische Philosophie und das Recht}

Seit dem 17. Jahrhundert hatte die politische Philosophie sich über die Vertragstheorien mit der Rechtsphilosophie verbunden, bis sie dann bei Kant und Hegel mit dieser verschmolz. Was üblicherweise als die politische Philosophie Kants angesehen wird, ist nichts weiter als ein Anhang seiner Philosophie des Rechts; so wie auch die politische Philosophie Hegels sich als eine Philosophie des Rechts darstellt, die in ihrem Untertitel Naturrecht und Staatswissenschaft verknüpft. ${ }^{5}$ Diese Verbindung ist in der zweiten Hälfte des 19. Jahrhunderts auseinandergebrochen, und im 20. Jahrhundert ist der Bruch noch verstärkt worden. Die liberale politische Philosophie hat zwar immer auf das Recht als Schranke vor Machtmissbrauch verwiesen und diese Schranke als Kriterium zur Unterscheidung von legitimer und illegitimer Machtausübung angesehen. Doch der ideologisch-politische Kontext, aus dem heraus sie ihre Analyse der liberalen Institutionen vornehmlich als deren Verteidigung gegen die Gefahren des Kollektivismus oder des Totalitarismus begriff, 
die, wie einige argwöhnten, in nucleo bereits in der Forderung nach sozialer Gerechtigkeit enthalten waren ${ }^{6}$, hat sie vernachlässigen lassen, worin die Stärke der politischen Philosophie des 17. bis 19. Jahrhunderts lag: in deren Reflexion auf den Beitrag des staatlichen Rechts zur Herausbildung des spezifischen Charakters moderner politischer Subjektivität. Diese Vernachlässigung konnte durch die kritische Philosophie nicht korrigiert werden; diese hat zumal unter dem Einfluss des Marxismus ihr Augenmerk im Wesentlichen auf die Logik des Ökonomischen und Sozialen gerichtet und das Recht auf den Status eines Machtinstruments verkürzt oder auf die Widerspiegelung von Kräfteverhältnissen, die sich wesentlich außerhalb des Rechts herausbilden. In ihren liberalen wie in ihren kritischen Varianten hat die politische Philosophie des 20. Jahrhunderts die zentrale Dualität der politischen Philosophien der vorhergehenden Jahrhunderte verkannt, die die Frage der Macht und die der Rechte miteinander verbunden hatten. Unter diesem Gesichtspunkt ist es bezeichnend, dass die modernen Souveränitätstheorien in erster Linie als Theorien zur Legitimierung der Staatsmacht gelesen wurden, und nicht als das, was sie auch waren: Theorien, mit denen sich eine Garantie der Rechte des Individuums im Rahmen einer Logik jenseits der Logik der Ständeprivilegien festmachen ließ. Die Ende des letzten Jahrhunderts bei einigen Philosophen wieder auftretende Thematik des »Rechtsstaats" - eines unzweifelhaft älteren Begriffs, der aber über einen längeren Zeitraum lediglich die Juristen oder, allerdings ausschließlich in Deutschland, die Vorläufer der Soziologie ${ }^{7}$ interessiert hatte - hat nicht dazu hingereicht, das verlorene Band zwischen politischem und juristischem Denken neu zu knüpfen.

4 Wie ist es heute damit bestellt? Zur gegenwärtigen Stunde hat eine praktisch unhinterfragte Übereinkunft die Tugenden der Demokratie abgesegnet. Demokratie gilt als Name für die gute Regierungsform. Die Frage ist nur, was darunter verstanden wird. Der Vielfalt der Interpretationen entspricht ein je unterschiedlicher Stellenwert, der dem Recht in der Bestimmung der Natur der Demokratie zugestanden wird. Manche setzen tendenziell Demokratie und Rechtsstaat schlicht gleich. ${ }^{8}$ Nicht immer wird wahrgenommen, dass diese Gleichsetzung die ursprüngliche Bedeutung des Worts Demokratie einschneidend modifiziert. Bildete die Demokratie für die antike Philosophie eine Regierungsform, jene, in der das Volk wirklich die Macht ausübt, so findet das Volk in der als Beschränkung der Macht durch Recht begriffenen Demokratie lediglich als abstrakte Einheit Eingang, von der her die Macht vorgeblich ihre Legitimität bezieht. Diese Art Legitimation führt eine Reihe institutioneller Konsequenzen mit sich, vor allem politische Rechte, die es dem Volk erlauben, sein Führungspersonal zu wählen. ${ }^{9}$ Doch wie Benjamin Constant sehr treffend bemerkt hatte: Ein Volk von Wählern regiert nicht - wenn es »zu festgesetzten, aber seltenen Zeiten « seine Souveränität ausübt, »dann immer nur, um darauf zu verzichten «. ${ }^{10}$

5 Auch wenn die Erfahrung des Totalitarismus, zumal der sowjetischen Spielart, jene Problemstellungen hat obsolet werden lassen, die formale und reale, politische und soziale Demokratie als unauflösliche Widersprüche gegenübergestellt haben - das kritische Denken hat damit seine Voreingenommenheiten gegenüber dem Recht nicht aufgegeben. ${ }^{11}$ Gewiss sind die meisten der Autoren, die dieser Strömung zuzurechnen sind, bereit einzuräumen, dass eine gute Regierung die »bürgerlichen« Freiheiten wie Meinungs- und Versammlungsfreiheit usw. akzeptieren muss; nicht abfinden aber wollen sie sich damit, dass Demokratie auf die Herrschaft des Rechts verkürzt wird, verstanden als Herrschaft staatsbürgerlicher Freiheiten und politischer Rechte, die sich 
auf aktives und passives Wahlrecht beschränken. Jenseits großer Unterschiede zwischen Autoren wie - um nur einige zu nennen - Lefort, Rancière und Negri eint diese doch eine gemeinsame Überzeugung: Der Begriff der Demokratie ist neu zu denken, wie auch deren Wirklichkeit in anderen als den politischen Praktiken in ihrer herkömmlichen Bedeutung gesucht werden muss. Für diese Autoren ist Demokratie nicht nur keine Regierungsweise oder Staatsform ${ }^{12}$, sie ist auch nicht Beschränkung der Macht durch das Recht, gewährleistet durch die minimalsten politischen Rechte, nämlich aktives und passives Wahlrecht. Die Wirklichkeit der Demokratie liegt nicht im Verwalten oder, wie es heute heißt, im Regieren, vielmehr im fortwährenden Hinterfragen derselben. Demokratie ist eine Bewegung, die unkoordinierte Bewegung vielfältiger Formen der Infragestellung institutionalisierter Machtinstanzen - und damit auch des Rechts, das immer im Verdacht steht, nurmehr Instrument der bestehenden Macht zu sein.

6 Michel Foucault bringt das wohl von einer ganzen kritischen Tradition der politischen Philosophie geteilte Vorurteil zum Ausdruck, wenn er das Recht im Allgemeinen dem »königlichen Befehlsrecht « gleichsetzt ${ }^{13}$ und damit im »Rechtssubjekt« nichts anderes sieht als jenes Subjekt, das, angeblich im Besitz von Naturrechten, bereit ist, darauf zu verzichten, das »den Verzicht auf sich selbst « akzeptiert, um die Herausbildung des souveränen Staats zu ermöglichen. ${ }^{14}$ Aus diesem Blickwinkel erscheint das Recht lediglich als Maske der Macht; deren Wirklichkeit besteht in Herrschaft - eine Wirklichkeit, die zu verschleiern der Theorie und Technik des Rechts als wesentliche Funktion aufgegeben ist. ${ }^{15}$ Zwangsläufig verhindert eine solche Interpretation des Rechts, in ihm einen der Faktoren zu sehen, der zur Gestaltung der modernen Subjektivität beigetragen hat. Auch wenn Foucault nie den Anspruch erhoben hat, seine Analysen gehörten zur politischen Philosophie, so hat sein Werk doch erheblichen Einfluss auf bestimmte Bereiche der zeitgenössischen politischen Philosophie ausgeübt. Nicht zuletzt ist es in hohem Maße dafür verantwortlich, dass die Modi der Subjektivation, der Subjektwerdung, Eingang in die politische Philosophie gefunden haben; wie Foucault auch, vielleicht ohne dass er es wollte, das Argument der Kritiker der Naturrechtsfiktion dadurch radikalisiert hat, dass er dazu aufforderte, Freiheit und Macht als sich wechselseitig bestimmend zu betrachten. Seine äußerst reduktionistische Auffassung von Recht hat ihn gleichwohl daran gehindert, aus seiner Kritik der »Repressionshypothese« die Konsequenzen zu ziehen, die es ermöglichen, dem Kampf um die Rechte jenen Stellenwert einzuräumen, der ihm in den für das moderne Individuum typischen Subjektivationsformen zukommt. ${ }^{16}$

7 Aus der vorangegangenen, wie auch immer summarischen Darstellung lässt sich die zentrale Aussage der nachfolgenden Seiten bestimmen: Ich plädiere für ein neues Bündnis zwischen der politischen Philosophie und den Diskursen über das Recht, worunter ich gleichermaßen die Rechtstheorien wie die Soziologie des Rechts verstehe. Von Seiten der Soziologie des Rechts werde ich bei Max Weber die Instrumente suchen, mit denen sich auf originelle Weise das Verständnis der Wechselbeziehung von Recht und Macht aktualisieren lässt. Scheint sich mir die Webersche Rechtssoziologie der zeitgenössischen politischen Philosophie anzuempfehlen, so deshalb, weil sie ungeachtet des wohlbekannten »Etatismus« ihres Autors - eine Definition von Recht vorschlägt, die ein nicht-etatistisches Recht zu denken erlaubt.

8 Das Hauptproblem, mit dem die politische Philosophie zu Beginn des 21. Jahrhunderts sich konfrontiert sieht, besteht in der Tat nicht nur darin, die Demokratie neu 
begrifflich zu fassen, sondern sie so zu fassen, dass der Gesamtheit der Phänomene, den rechtlichen und den politischen, Rechnung getragen wird, die zusammen mit den ökonomischen Phänomenen, mit denen sie einhergehen, das ausmachen, was unter dem Begriff der Globalisierung verstanden wird, zu deren entscheidenden Aspekten die Aushöhlung des Rechtsmonopols des Staates zählt. Indem sie Demokratie als Bewegung versteht und nicht mehr nur als eine Staats- oder Regierungsform, hält die kritische politische Philosophie die Tatsache fest, dass Demokratie angemessen erfassbar nur in ihrer Geschichte ist. Was heißt: nicht als Produkt dieser Geschichte, sondern als diese Geschichte selbst, als Geschichte der Praxis der Demokratie, die seit der Epoche der sie inaugurierenden Revolutionen ein nie zum Stillstand gekommener Prozess der Institutionalisierung und Infragestellung der Institutionen gewesen ist. Diese Realität die der modernen Demokratie - setzt nicht nur, wie Claude Lefort schon seit längerem hervorgehoben hat ${ }^{17}$, eine Veränderung des Politikbegriffs voraus, sondern in eins damit einen Wandel von anthropologischer Tragweite. Denn sie vollzieht einen Bruch mit den starren Identitäten oder, genauer, sie führt die Auflösung der statutarischen Zugehörigkeiten innerhalb des Rahmens der westlichen Geschichte zu einem Abschluss. Das moderne Subjekt ist politisch nicht deshalb, weil es eine statutarische Identität gegen eine staatsbürgerliche Identität austauscht, die es der Annahme zufolge mit »allen« teilt (bekanntlich handelt es sich immer um eine partikulare Universalität, die der Bürger eines Staates). Es ist politisch insofern, als seine Identität definiert ist anhand von Rechten, die nicht ein für allemal feststehen, vielmehr in Kämpfen erworben werden nicht gegen die Institution als solche, sondern gegen die Versteinerung der Institution.

Diese letzte Konsequenz aus dem historischen Charakter des modernen politischen Subjekts wird durch ein etatistisch fixiertes politisches Denken verdunkelt. Solange politische Subjektivität in Begriffen der nationalen Staatsbürgerschaft interpretiert wird, bleibt sie eine Form von kommunitaristischer Zugehörigkeit und bewahrt etwas Statutarisches. In gewisser Weise vollenden die zeitgenössischen politischen und rechtlichen Veränderungen den mit der Abschaffung der Stände und Privilegien begonnenen Prozess. Noch heute Demokratie ausschließlich im Rahmen des Staates zu denken heißt, sie unvollständig und jedenfalls anachronistisch zu denken und sich, wird die Frage der Ausländer oder supra- bzw. transnationaler Machtinstanzen und Institutionen angeschnitten, unüberwindbaren Aporien auszusetzen.

\section{Der Begriff der subjektiven Rechte bei Max Weber und bei den Rechtstheoretikern}

\section{Von Weber zu Hobbes}

10 Mit der politischen Soziologie Webers lässt sich das Recht von seiner eng etatistischen Bedeutung loslösen. Hier möchte ich nur kurz die Analyse-Ergebnisse vergegenwärtigen, die ich an anderer Stelle entwickelt habe. ${ }^{18}$ Die politische Soziologie Webers ist unbestreitbar eine Staatssoziologie in dem Sinne, dass Weber im modernen souveränen Staat mit seinem Monopol an legitimem Zwang die vollendete Gestalt der politischen Gemeinschaft gesehen und ein Jenseits des Staats nicht in Betracht gezogen hat. Allerdings ist dieses Staatsverständnis einer wechselseitig sich bedingenden Geschichte von politischen Gemeinschaften und Recht eingeschrieben, die einen 
weiteren, seine strikt etatistische Bedeutung einschließenden und zugleich über ihn hinausgehenden Rechtsbegriff voraussetzt. Sich von der gemeinsamen Übereinkunft der Juristen seiner Zeit absetzend, schlägt Weber Soziologen wie Historikern eine Definition von Recht vor, in Bezug auf die das etatistische Recht nur einen Einzelfall darstellt. Diese weitere Bedeutung gilt für das objektive Recht wie die subjektiven Rechte. Bezogen auf ersteres, hält Weber als entscheidendes Element "die Existenz eines Erzwingungs-Stabes« fest. Und fährt dann fort: "Dieser braucht natürlich in keiner Art dem zu gleichen, was wir heute gewohnt sind. Insbesondere ist es nicht nötig, daß eine >richterliche Instanz vorhanden sei.« ${ }^{19}$ Webers Begriff des >subjektiven Rechts` ist dazu streng parallel entwickelt. Eine Person verfügt über ein ssubjektives Recht ‘, wenn sie »die durch den einverständnismäßig geltenden Sinn einer Rechtsnorm faktisch garantierte Chance (hat), für bestimmte (ideelle oder materielle) Interessen die Hilfe eines dafür bereitstehenden \Zwangsapparates« zu erlangen.$^{20}$ Dies setzt die mögliche Unterscheidung zwischen »subjektive[m] Recht im sstaatlichen Sinn des Wortes«, das »unter der Garantie der Machtmittel der staatlichen Gewalt» steht, und ")außerstaatlichem` Recht" voraus, wo "Zwangsmittel einer anderen als der politischen Gewalt in Aussicht stehen « - Weber nennt hier beispielhaft hierokratische Gewalt. $^{21}$

Wird die hier vorgeschlagene extensive Auffassung des Rechts zugrunde gelegt, erscheint der moderne Staat als Ergebnis eines Prozesses, in dem ein bestimmter Typ von Gemeinschaft - dadurch auch zur politischen Gemeinschaft schlechthin erhoben das Monopol auf Ausübung legitimen Zwangs erwirbt auf Kosten jener unterschiedlichen »Rechtsgemeinschaften« (feudale Mächte, Stände, Kirchen, Städte usw.), die einstmals ihren Mitgliedern partikulare Rechte garantierten, mit anderen Worten Privilegien, also statutarische Rechte. Kurzum, der moderne Staat hat dem anarchischen Pluralismus - verstanden in dem Sinne, dass die vielfältigen »Rechtsgemeinschaften" kein hierarchisiertes Ganzes bildeten - ein Ende gesetzt, einem rechtlichen und gleichzeitig politischen Pluralismus, der die allgemeine Voraussetzung des Feudalsystems des okzidentalen Mittelalters darstellte. Die Monopolisierung der Rechtsgarantie durch den Staat ging einher mit der von Weber so bezeichneten "Mediatisierung" partikularer Rechte. Ist dieses Monopol einmal errichtet, sind die Rechte, über die ein Einzelner aufgrund seiner Zugehörigkeit zu einer besonderen Gemeinschaft verfügen kann, nur legitim kraft der expliziten oder impliziten Ermächtigung durch den Staat. Von allen vorhergehenden politischen Gemeinwesen unterscheidet sich der moderne Staat darin, dass er gefordert und in der Regel auch erreicht hat, »dass diese Sonderrechte nur kraft [seiner] Zulassung in Geltung bleiben und also auch nur soweit, als [er] es erlaubt «. ${ }^{22}$

Diese »Mediatisierung" der partikularen Rechte steht in Wechselbeziehung zur Individuierung des Rechtssubjekts. ${ }^{23}$ Der Fortbestand von Rechten innerhalb des Raums der staatlichen Gewalt, die bestimmten Gruppen von Individuen vorbehalten sind, oder die Schöpfung neuer derartiger, d.h. statutarischer Rechte im Zusammenhang etwa mit der Ausübung bestimmter Berufe, stellen in Bezug auf die Universalität des Gesetzes keine Ausnahme dar. Die Zeiten sind vorbei, da der Einzelne sein »Rechtsbekenntnis« mit sich trug und anhand dieses "Bekenntnisses « seinen Unterschied gegenüber den Anderen geltend machte, d.h. gegenüber denjenigen, die diese Rechte nicht in Anspruch nehmen konnten. Das "personalisierte « Recht ist zugunsten des allgemeinen Gesetzes verschwunden, das für alle Bewohner des Territoriums gilt, auf dem die 
Staatsgewalt ausgeübt wird (lex terrae). Eine der starken Thesen des langen Kapitels aus Webers Wirtschaft und Gesellschaft, das den subjektiven Rechten gewidmet ist, lautet, dass die Herausbildung des modernen Staats einherging mit einer tiefgreifenden Wandlung im Verständnis dessen, was Rechte sind. Aus dieser Perspektive ist es weniger wichtig, dass auch im komplexen Funktionsaufbau staatlicher Gesellschaften noch Elemente statutarischer Logik zu finden sind. Insofern partikulare Rechtssphären nur kraft des Staats existieren können, ist das einzige reale Rechtssubjekt das Individuum als solches, abstrahiert von seinen diversen Zugehörigkeiten zu wie auch immer gearteten Gemeinschaften, sei es Familie, Beruf, Religionsgemeinschaft usw. Dieser grundlegende Individualismus in der modernen Konzeption des Rechtssubjekts ist von dem am wenigsten liberalen Theoretiker der modernen Souveränität, Thomas Hobbes, wahrgenommen und herausgestrichen worden. ${ }^{24}$ In dieser Hinsicht ist ein häufig vernachlässigtes Kapitel des Leviathan, das 22., höchst lehrreich. In diesem »Von den politischen und privaten Vereinigungen der Untertanen« (»Of Systems Subject, Political, and Private«) betitelten Kapite ${ }^{25}$ stellt Hobbes fest, dass zeitlich begrenzte oder dauerhafte Körperschaften außer dem Staat nur durch explizite (schriftliche) oder implizite Autorisierung durch die "souveräne Gewalt« legitim bestehen können. Mit der Konsequenz, dass der Einzelne immer die Fähigkeit bewahrt, sich davon loszusagen, sei es im Fall eines von einer solchen Vereinigung vertraglich festgehaltenen Darlehens, wo es »für einen einzelnen nicht nur rechtmäßig, sondern auch zweckmäßig ist, gegen die Beschlüsse der repräsentativen Versammlung offen zu protestieren«, sei es allgemein bei jedem Streitfall, wo ein Einzelmitglied einer einzelnen "politischen Körperschaft" gegenübertritt und es dem Souverän (dem Staat) zukommt zu urteilen, und nie der einzelnen Körperschaft selbst. ${ }^{26}$ Aus dieser Analyse ergibt sich die Schlussfolgerung, dass - anders als Foucault in der bereits zitierten Passage behauptet - das Rechtssubjekt der Vertragstheorien nicht das "Subjekt ist, das die Negativität akzeptiert, das den Verzicht auf sich selbst akzeptiert « ${ }^{27}$, sondern weit eher das Subjekt, das sich als von aller statutarischen Determiniertheit befreites und in ebendieser puren Vereinzelung Rechte wahrnehmendes Individuum selbst erobert.

\section{Subjektive Rechte und Naturrecht: zwei angefochtene Begriffe}

Michel Villey, ein scharfer Kritiker der Figur des »Rechtssubjekts«, hat also mit seiner Behauptung, diese Figur sei Erfindung der Modernen, nicht Unrecht. ${ }^{28}$ Diese historische Bestimmung ist allerdings kein ausreichendes Argument, um deren Relevanz in Abrede zu stellen, es sei denn, man verteidigte eine unwandelbare, d.h. essentialistische Konzeption des Rechtlichen (was auf Villey genau zutrifft). Mit der Kritik der Figur des Rechtssubjekts ist verknüpft die der Begriffe des subjektiven Rechts und des Naturrechts (im modernen Sinn von mit der menschlichen Natur verbundenen Rechten). Bekanntlich sind die beiden letztgenannten Begriffe zahlreichen Rechtstheoretikern, darunter den bedeutendsten, suspekt, ja unannehmbar erschienen. Was den Begriff des »Naturrechts « anbelangt, so war die Kritik eine Zeit lang einhellig: Wenn auch mit unterschiedlichen Argumenten, wird er von Georg Jellinek, Léon Duguit und Hans Kelsen gleichermaßen zurückgewiesen. Der Begriff von Rechten des Individuums ist außerhalb des Rahmens des Staates (Jellinek, Kelsen) bzw. der Gesellschaft (Duguit) undenkbar. Allerdings ist es zweifelhaft, ob die modernen Theoretiker des Naturrechts wirklich so naiv waren, wie ihre Kritiker des 20. Jahrhunderts es glauben machen wollen. Was die Kritik der Juristen des 
20. Jahrhunderts bei ihrer Stigmatisierung der Vorstellung eines Naturrechts verkennen, ist die historische Bedeutung der "Naturalisierung" der Rechte. Darin kommt die Individuierung des Rechtssubjekts zum Ausdruck, die, wie bereits angemerkt, nur in einer konstitutiven Beziehung zu jener besonderen Ausprägung der politischen Macht: dem modernen souveränen Staat, begrifflich fassbar wurde. Weil aus der Perspektive des Staates das Individuum sich Rechte nur in seiner nackten Singularität anerkennen lassen kann, und nicht aufgrund irgendeiner statutarischen Zugehörigkeit, können diese Rechte (oder Teile derselben) als »natürliche« erscheinen. Die Verwechslung von physischer oder genauer physisch-moralischer Individualität und politischer Individualität ist Produkt der Ausradierung statutarischer Unterschiede. In der berühmten, gemeinhin ökonomisch-gesellschaftlich interpretierten Formulierung von Marx, der Mensch sei ein Lebewesen, das sich nur in Gesellschaft vereinzelt, steckt, wenn man will, eine politisch-rechtliche Wahrheit. Anders als eine oberflächliche Kritik ihnen zuschreibt, haben die Theoretiker des »Naturrechts« sich keine ahistorische menschliche "Natur« erträumt; sie haben vielmehr die anthropologischen Konsequenzen einer entscheidenden historischen Veränderung festgehalten: Die politische Individualität ist von nun an nicht mehr durch Zugehörigkeiten zu natürlichen Gemeinschaften (wie es die Gemeinschaften bei Aristoteles waren) definiert, sondern durch ihr Verhältnis zu einer einzigen und für alle gleichen Macht, die ihr Rechte, die ihre ganze politische Realität ausmachen, je nachdem zu- oder aberkennt.

Hinsichtlich des Begriffs des subjektiven Rechts ist die Kritik der großen Rechtstheoretiker aus der ersten Hälfte des 20. Jahrhunderts weniger einmütig; in ihren Meinungsunterschieden treten denn auch die unterschiedlichen Prämissen ihrer scheinbar einhelligen Kritik des Naturrechts ans Licht. Léon Duguit etwa weist den einen wie den anderen Begriff zurück; den Doktrinen des Naturrechts wirft er nicht vor, von der Annahme ausgegangen zu sein, das Recht sei unabhängig vom Staat denkbar, sondern dessen Begriff ausgehend vom isolierten Individuum bestimmt $\mathrm{zu}$ haben. Diesen Doktrinen zufolge, so seine Behauptung, ist das Recht eine Eigenschaft des Menschen, »begriffen im Zustand absoluter Isolierung, ohne irgendeine Beziehung $\mathrm{zu}$ Seinesgleichen «. ${ }^{29}$ Ungeachtet dessen vertritt er die These, wonach die Konsistenz des Rechtsbegriffs durchaus nicht zurückführbar sei auf die ihm durch den Staat gewährte Garantie (»Der Mensch hat das Recht konzipiert, bevor er den Staat konzipiert hat, und nicht den Staat, bevor er das Recht konzipierte $\aleph^{30}$ ), da es anders unmöglich wäre, die Macht des Staates durch das Recht zu beschränken. Der Wahrheitskern der Naturrechtsdoktrinen beruhte in ihrer Absicht, der Begrenzung der Macht, ihre Schwäche in ihrem Individualismus. Dieser erlaubte ihnen zwar, die negativen Pflichten des Staates (die Freiheitsrechte) zu begründen, nicht aber die ebenfalls dem modernen Staat zufallenden positiven Pflichten (die sozialen Rechte).

Mit der These, das Recht sei älter als die Macht des Staates, und unter Berufung auf eine von Durkheim inspirierte solidaristische Konzeption des Rechts (das Recht ist eine Verhaltensregel, keine Eigenschaft eines Subjekts) wollte sich Duguit nicht zuletzt von den deutschen Doktrinen (Hegel, Laband, Ihering, Jellinek) absetzen, denen er vorwarf, Recht und staatlichen Zwang gleichgesetzt und damit die Begrenzung der Macht aus dem Bereich des Denkbaren ausgeschlossen zu haben. Dass er diese Kritik auch auf Jellinek ausdehnt, der zwar Theoretiker der subjektiven Rechte war, aber doch mit Duguit den Willen teilte, den Staat dem Recht zu unterwerfen, mutet auf den ersten 
Blick paradox an. Duguits Vorwurf an seine deutschen Zeitgenossen besteht darin, dass sie parallel auch dem Staat den Status eines Rechtssubjekts zugesprochen und damit in einer subtileren Version die Personifizierung der Gemeinwesen, ja die Hypostasierung des Staates weitergeführt hätten, die ihre Vorgänger in organizistischer oder historizistischer Form betrieben hatten. Duguit zufolge - der damit, wie ersichtlich, der herkömmlichen Axiomatik des liberalen Denkens sehr fern steht - besteht ein enger Zusammenhang zwischen dem Begriff des subjektiven Rechts und der Hypostasierung des Staates.

16 Jellinek gehört der von Duguit so vehement attackierten deutschen Tradition insofern an, als der Rechtsbegriff für ihn an Zwang oder, genauer, an die staatliche Garantie gebunden ist. ${ }^{31}$ An diesem Punkt divergiert er von den Naturrechtsdoktrinen (denen er zugesteht, die Rechte solide auf die menschliche Natur gegründet zu haben), deren Kritik ihm indessen minder wichtig erscheint als Duguit. Bekanntlich stand Jellinek Weber nahe; wie sehr ihre Auffassungen von Recht und Staat einander ähnelten, zeigt sich an den historischen Erwägungen, von denen aus Jellinek seine Rechtstheorie entwickelt: Das Recht, so konzediert er, war sicher nicht immer Sache des Staats, aber in der Geschichte des modernen Okzidents wird sichtbar, wie der Staat fortschreitend alle Machtmittel der untergeordneten Kollektivitäten an sich zieht; am Ende dieses Prozesses ist der Staat »alleiniger Inhaber der Befehlsmacht « ${ }^{32}$ In den Worten Jellineks, die Duguit zitiert:

»Dadurch wird zwar nicht die gesamte Rechtsbildung, wohl aber der rechtlich geordnete Rechtsschutz Sache des Staates. Die Gerichtsgewalt geht ausschließlich in seine Hände über, und alle Gerichtsbarkeit ist daher zuletzt entweder ihm zugehörig oder von ihm geliehen. Damit wird es endlich des Staates Recht, alles innerhalb seiner Grenze geltende Recht zu regulieren, so daß im modernen Staate alles Recht in staatlich geschaffenes und staatlich zugelassenes Recht zerfällt..«33

Indes hat Jellinek den Hauptteil seiner wissenschaftlichen Arbeit nicht dieser Vorgeschichte des modernen Staates gewidmet, sondern den Voraussetzungen seiner rein rechtlichen Intelligibilität. Für mich liegt das Hauptinteresse seines Vorgehens darin, dass er den Begriff der subjektiven Rechte abtrennt von der Fiktion aus der Natur des Menschen sich ergebender Rechte. Auf die ihm eigene Art hat Jellinek erneut das letztlich zentrale Problem der Vertragstheorien (der modernen Theorien des Naturrechts) aufgerollt: den korrelativen Nachweis der Legitimität des Rechtsmonopols des Staates und der Rechte der Einzelnen.

Auch bei Kelsen findet sich die Kritik des Begriffs des subjektiven Rechts verbunden mit der des Naturrechts. Sicher ist seine Kritik der Naturrechtsdoktrinen zunächst geleitet von der Absicht, den streng positiven (und für ihn damit wissenschaftlichen) Charakter der reinen Rechtslehre geltend zu machen. Deren Positivismus impliziert, jeden »ethisch-normativen « Gesichtspunkt fernzuhalten: Diese Theorie handelt von der Form des Rechts, d.h. der Logik des Rechts, verstanden als System von Normen, und nicht von dessen Inhalt. Darauf beharrt Kelsen insbesondere in Bezug auf die Interpretation der "Grundnorm «, jenes Begriffs, den er als abschließendes Prinzip eines Systems von Normen einführt, das dieses als Rechtsordnung zu denken erlaubt. ${ }^{34}$ Die Grundnorm ist die transzendentale Bedingung der rechtlichen Interpretation des Rechts, sie hat lediglich eine »erkenntnistheoretische Funktion $\aleph^{35}$ und ist kein Kriterium zur klaren Unterscheidung zwischen gerechten und ungerechten Rechtsordnungen. Sie kann also nicht verwechselt werden mit einer Naturrechtstheorie, die, ist sie konsequent, den Grund der Geltung des positiven Rechts »in einem von dem positiven Recht 
verschiedenen Naturrecht " suchen muss. ${ }^{36}$ In dieser Charakterisierung der Naturrechtstheorien finden weder das subjektive Recht Erwähnung noch, allgemeiner, die Figur des Rechtssubjekts. Das Bindeglied zwischen der den Naturrechtstheorien inhärenten ethisch-normativen Funktion und dem Begriff des subjektiven Rechts ist das Postulat, dass vorrechtliche Entitäten auf die eine oder andere Weise Zwänge auf die objektive Ordnung des positiven Rechts ausüben können. Dieses Postulat teilen mit den Naturrechtstheorien alle Rechtstheorien, die zwischen subjektivem und objektivem Recht unterscheiden, was immer darauf hinausläuft, jenem den Vorrang gegenüber diesem einzuräumen. Kelsens Argument steht seit der Reinen Rechtslehre fest $^{37}$, und er wird es bis zu seinem letzten Werk, dem 1979 postum erschienenen Allgemeine Theorie der Normen wiederholen. ${ }^{38}$ Gegen die »irrige Anschauung von dem Primat des subjektiven Rechts gegenüber der Pflicht $^{39}$ wendet Kelsen ein, vom Gesichtspunkt einer strikt positiven Theorie des Rechts setze ein subjektives Recht nicht nur eine entsprechende Pflicht voraus, sie »ist« vielmehr »diese Rechtspflicht «. ${ }^{40}$

Naturrechtstheorien sind nicht zwangsläufig Theorien subjektiver Rechte (obwohl Kelsen darüber nichts sagt, kann die »ethisch-normative« Funktion einer derartigen Theorie sich auf eine Gesamtanschauung der Weltordnung stützen, unter Bezug auf einen transzendenten Ursprung, ohne zu implizieren, dass das Individuum/Subjekt Rechte besitzt); aber alle Rechtstheorien, die Recht und Pflicht unterscheiden, sind Erben des Begriffs des Naturrechts:

„Die traditionelle Anschauung, daß das Recht ein von der Pflicht verschiedener Gegenstand der Rechtserkenntnis sei, daß jenem sogar die Priorität diesem gegenüber zukommt, ist wohl auf die Naturrechtslehre zurückzuführen. Diese geht von der Annahme natürlicher, dem Menschen eingeborener Rechte aus, die vor jeder positiven Rechtsordnung existieren; und unter denen das subjektive Recht des individuellen Eigentums eine Hauptrolle spielt. Die Funktion einer den Naturzustand beendigenden positiven Rechtsordnung (des Staates) ist, dieser Anschauung zufolge, die natürlichen Rechte durch Statuierung von korrespondierenden Pflichten zu garantieren. $\ll^{41}$

Kelsens Ansatzpunkt der Kritik des Naturrechtsbegriffs ist offensichtlich ein anderer als bei Duguit; dieser focht nicht an, sondern vertrat vielmehr die These, die Geltung des Rechts entspringe Realitäten, die vor und unabhängig von staatlichem Zwang existieren. Den Naturrechtsdoktrinen warf Kelsen nicht ihren Individualismus vor, sondern die Umkehrung der logischen Ordnung der Begriffe Pflicht und Recht. Ihm zufolge beruht die rechtliche Substanz des Rechts (und es gibt keine andere) ausschließlich in der Pflicht. Er verwirft zwar nicht völlig den Gebrauch des Begriffs "subjektives Recht« (aus sprachlicher Bequemlichkeit, nicht weil er zur Beschreibung des Rechts unabdingbar wäre), aber nur unter der Voraussetzung, sich der Antithese zwischen subjektivem und objektivem Recht zu entledigen. Was "subjektives Recht" genannt wird, ist allermeist ein »Reflexrecht«, d.h. die Interpretation der Pflicht, die die Rechtsnorm vom Gesichtspunkt des Individuums aus setzt, dem ein anderes Individuum verpflichtet ist, wobei sie Zuwiderhandlungen gegen diese Pflicht mit Strafe bedroht. Inhaber subjektiver Rechte ist nicht das wirkliche »Rechtssubjekt « vorausgesetzt, man beharrt auf dieser "personalistischen Sprache", der Kelsen selbst misstraut ${ }^{42}$-, sondern das Subjekt der Rechtspflicht, d.h. das ihr unterworfene Individuum. ${ }^{43}$ So billigt Kelsen dem Begriff des subjektiven Rechts Unabhängigkeit gegenüber dem Pflichtbegriff (subjektives Recht im »technischen Sinne « ${ }^{44}$ ) auch nur in dem ganz besonderen Fall zu, wo bestimmte Rechtsordnungen dem Einzelnen die 
Möglichkeit einräumen, selbst ein Verfahren zwecks Bestrafung desjenigen in Gang zu setzen, der der Pflicht zuwidergehandelt und ihn damit geschädigt hat.

Mein kurzer Abstecher in die Rechtstheorie hatte lediglich zum Ziel, darauf hinzuweisen, dass der Begriff der subjektiven Rechte zwar heftig diskutiert wird, aber nicht als juridischer Unsinn dogmatisch abgetan werden kann. Wie auch immer Michel Villey darüber gedacht haben mag, dieser Begriff kann durchaus, wie ja auch das Beispiel Jellinek gezeigt hat, von der Hypothese einer vor aller rechtlichen Bestimmung feststehenden menschlichen Natur abgekoppelt werden. Man kann sich von der Vorstellung einer unwandelbaren Menschennatur verabschieden, ohne darauf verzichten zu müssen, das Universum des Rechts mit gesellschaftlichen und politischen Realitäten zu verbinden, die es übersteigen, auch wenn es eines ihrer Komponenten ist. Um dies tun zu können, muss allerdings anerkannt werden, dass die Rechtsinstitution, wie essentiell sie für das Dasein des Rechts als solchen (objektiv und subjektiv) auch sei, häufig, wenn nicht immer, die Bedeutung einer Anerkennungsinstanz hat. Eine der Schwierigkeiten der Position Kelsens besteht darin, dass er, indem er jegliche andere "Quelle des Rechts« als die Rechtsordnung des Staates für untauglich erklärt ${ }^{45}$ und den Begriff des Rechtssubjekts so umdeutet, dass er nicht mehr den Inhaber subjektiver Rechte bezeichnet, sondern das der Pflicht unterworfene Individuum, er zugleich damit die Vorstellung ausschließt, dass das Recht als Anerkennung vorgängiger Ansprüche interpretiert werden könne. Was die positive Rechtstheorie zurückweist, ist

»die Vorstellung eines von der Rechtsordnung unabhängigen Rechtswesens [...], einer Rechtssubjektivität, die das Recht, sei es im Individuum, sei es in gewissen Kollektiven, sozusagen vorfindet, die es nur anzuerkennen hat und notwendigerweise anerkennen muß, wenn es seinen Charakter als $>$ Recht $\_$nicht verlieren will«. ${ }^{46}$

Unübersehbarer Zweck dieses Textes ist die Ablehnung der Vorstellung, wonach die Rechtsinstitution sich auf die Registrierung gegebener, d.h. unwandelbar festgelegter Rechte beschränkt, für deren Respektierung und zugleich Gewährleistung der von der Rechtsordnung nicht unterschiedene Staat eintritt. Allerdings schließt er auch eine ganz andere These aus, wonach nämlich das positive Recht in dem Maße, wie es historisch geworden ist, zunächst nur als Ansprüche vorliegende Forderungen in Rechte verwandelt und damit eine gesellschaftliche Realität zum Ausdruck bringt, in deren Entwicklung es um die Bestimmung der politisch-rechtlichen Individualität des Menschen geht.

Nun setzt diese These in der Tat voraus, dass dem historischen Charakter des politischen Subjekts Rechnung getragen wird, eine von den epistemologischen Prämissen der reinen Rechtslehre a limine ausgeschlossene Perspektive. Was Kelsen als "Rechtsdynamik" bezeichnet, wobei das Recht in der fortwährend erneuerten Bewegung seiner Selbstschöpfung betrachtet wird, ist nicht die Geschichte insofern, als in jedem bestimmten Fall die Kohärenz einer positiven Rechtsordnung die Formen dieser steten Schöpfung festlegt. Kelsen war Demokrat, aber er konzipierte die Demokratie als einen Modus der Schöpfung von Recht, einer Rechtsordnung, die eine verschieden gestaltete Teilhabe des Volkes an ihrer eigenen Schöpfung institutionalisiert. ${ }^{47}$ Obwohl er sich dadurch von den üblichen Demokratieauffassungen absetzen wollte, die Demokratie als Regierungs- oder politische Form definieren, steht er diesen doch insoweit nicht so fern, als er nicht zulassen mochte, dass die Infragestellung der legalen Ordnung selbst, in ihrer Gänze oder in einer ihrer Erscheinungsformen, uneingeschränkt zur Realität der modernen Demokratie gehört. 


\section{Die politische Philosophie als Philosophie der subjektiven Rechte}

21 Wie sich gezeigt hat, werden aus der rechtlichen Kritik des Begriffs des subjektiven Rechts unterschiedliche Schlussfolgerungen gezogen. Nichtsdestoweniger hat die Kritik dieses Begriffs einige Bedingungen für seinen Einsatz im Rahmen einer politischen Philosophie festzulegen erlaubt, die, wie ich vorschlagen möchte, ihr Denken und insbesondere ihre Interpretation der modernen Demokratie wieder stärker auf den Begriff der Rechte statt auf den der Macht zentriert. Dabei versteht sich zuvorderst ganz von selbst, dass die für die moderne politische Individualität konstitutiven Rechte nicht als ontologische Eigenschaften eines Subjekts zu gelten haben, dessen Identität unabhängig von der historischen Entwicklung gegeben ist. Näher betrachtet, verschlossen sich die statutarischen Identitäten, obgleich auf Geschichte sich berufend, der Historizität sehr viel stärker als das nicht statutarisch fixierte Individuum der Vertragstheorien. Die Statute, die Rechtsstellungen, das war versteinerte Geschichte, war Anrufung in ferner Vergangenheit fixierter ungleicher Rechte, die sich anmaßten, Gegenwart und Zukunft zu normieren. Die von den Ordnungen des Ancien Régime gegen die reformerischen Initiativen der Fürsten in Anschlag gebrachten Rechte waren unwandelbare Rechte, zwar Hilfsmittel gegen die tendenzielle Schrankenlosigkeit der souveränen Macht, also gegen den Absolutismus, aber auch solche, die Ungleichheiten aller Art (ökonomische, politische, rechtliche) auf Dauer stellten. Dem gegenüber stellte die Individuierung der Rechte den Ausgangspunkt einer Historisierung dar, was die letzten zwei Jahrhunderte der Geschichte des Okzidents veranschaulichen, in denen das Feld der den Individuen durch Verfassungs- wie Gesetzestexte anerkannten und ihren Bürgern durch die Staaten verbürgten Rechte erweitert wurde. Dieser Geschichte eignet weder Notwendigkeit noch Linearität. Die Anerkennung neuer Rechte wurde den Machtinstanzen häufiger abgenötigt als von diesen aus freien Stücken zugestanden und es gab Rückschläge. Am Rande sei festgehalten, dass die Individuierung des Rechtssubjekts nicht bedeutet, dass die Kämpfe um die Rechte individuell geführt worden sind. Im Gegenteil, meistens waren sie ein kollektiver Akt, d.h., dass es eine Sozialgeschichte der Kämpfe um Eroberung und Verteidigung von Rechten gibt, eine Geschichte, in der sich ein demos zum Ausdruck bringt, der weder die abstrakte Körperschaft ist, auf die sich demokratische Verfassungen in ihren Präambeln berufen, noch die Totalität der realen Mitglieder eines Staates. ${ }^{48}$ Doch die Öffnung der Geschichte der Rechte, die Möglichkeit neuer Rechte und nicht nur das neuerliche Geltendmachen der Unantastbarkeit der eingeführten Rechte steht in unmittelbarem Zusammenhang mit ihrer Individuierung, d.h. auch der Unbestimmtheit der "Menschenrechte«, in der einige ihre Schwäche gesehen haben; aber gegenüber den statutarischen Freiheiten bietet jene auch den Vorteil, dass die "Menschenrechte« eine noch leere und deswegen erst noch evolutionär zu füllende, gesellschaftlichem Handeln zugängliche Form darstellen.

Die rechtliche Kritik des Begriffs des subjektiven Rechts bringt uns auch dazu, die Macht der Institution ernst zu nehmen. Der bloße Anspruch auf ein Recht, wie immer gerechtfertigt aus der Warte eines alltagspraktischen Gerechtigkeits- und Ungerechtigkeitssinns, ist kein Recht. Recht im eigentlichen Sinn des Wortes besteht nur unter der Voraussetzung seiner Gewährleistung durch eine Macht, der des Staates im Paradigma der oben erwähnten Rechtstheorien, oder jeder anderen über 
Zwangsmittel verfügenden Instanz, folgt man Weber. Um dem, was seit zwei Jahrhunderten Realität der Demokratie gewesen ist, gerecht $\mathrm{zu}$ werden, ist es unabdingbar, in ihr Konzept auch die außer-rechtlichen und außer-politischen Praktiken einzuschließen, die die legale Ausübung der Macht unablässig und auf mehr oder minder scharfe Weise in Frage gestellt haben (insofern sie den durch Verfassungsund Gesetzestexte definierten, aber eben auch beschränkten Rahmen des politischen Handelns sprengten). Es ist mithin notwendig, sich von einer engen rechtlichen Konzeption der Demokratie zu lösen, die jegliche Infragestellung der instituierten Mächte der Subversion zuschlägt. Nicht minder notwendig aber auch zu begreifen, dass der Infragestellung eines gegebenen Zustands der Macht und ihrer rechtlichen Gestaltung nur unter der Voraussetzung politische Bedeutung zukommt, als sie auf eigene institutionelle Umsetzung zielt. Hegel plagiierend, könnte man sagen, die Angst vor der Institution sei das Schibboleth, an dem sich die falschen Brüder und die falschen Freunde der Demokratie erkennen ließen, oder, genauer noch, die unheilbaren Romantiker, die die Substanz der Demokratie in den Momenten des revolutionären Aufbrausens suchen, jenen Augenblicken, in denen die instituierten Machtinstanzen schweigen oder nicht mehr gehört werden, sodass die Vorstellung aufkommen kann, sie existierten nicht mehr. ${ }^{49}$

23 Vorausgesetzt, sie erfüllt diese beiden Bedingungen, kann eine historisch-kritische Auffassung der Demokratie vom Begriff der subjektiven Rechte profitieren, ohne ein Wesen des Menschen postulieren zu müssen. Dass die Formulierung von Naturrechten ebenso performativen Charakter hat wie die von Menschenrechten, ist eine Binsenweisheit. Diese Rechte haben, bevor sie geäußert, damit festgestellt und instituiert sind, keine Existenz. Die subjektiven Rechte im Allgemeinen sind nicht an eine Identität des Subjekts gebunden, die vor ihrer Eroberung und Anerkennung bestimmt und garantiert wäre. Doch die fehlende statutarische Definition des "Menschen«, der seine Rechte nur durch den Staat erwirken kann, verleiht dessen Identität eine Plastizität und schafft damit Raum für eine Praxis der Demokratie in dem Sinne, den der Begriff unter den Bedingungen der modernen Gesellschaften abdeckt und der von seiner etymologischen Bedeutung wie auch seinen älteren Interpretationen weit entfernt ist. Jacques Rancière schreibt an einer Stelle: „Die `Menschen- und Bürgerrechte sind die Rechte derer, die ihnen Wirklichkeit verleihen« 50; dieser Formel ist zuzustimmen, sofern darunter verstanden wird, dass die Identität des demokratischen Subjekts eine Identität im Werden ist, zu deren Bestimmung die Kämpfe gegen die von den legalen Mächten verordneten Regeln ebenso beitragen wie diese Regeln selbst. Anfechtbar erscheint mir dagegen die Behauptung, »das demokratische Leben" sei "ein politisches Leben unabhängig von der staatlichen Sphäre « ${ }^{51}$, insofern allein die Macht (des Staates oder, gegebenenfalls, anderer Zwangsinstanzen) jene Umwandlung der Forderungen in Rechte zu vollziehen vermag.

Eine wichtige Konsequenz der in den vorangegangenen Analysen entwickelten Interpretation der Demokratie sei hier wenigstens kurz erwähnt. Sie fordert dazu auf, die Relevanz der Unterscheidung zwischen bürgerlichen Rechten, politischen Rechten und sozialen Rechten zu hinterfragen, ja die gemeinhin den "Menschenrechten" vorbehaltene Sonderstellung in Frage zu stellen. Es geht nicht darum, die Brauchbarkeit dieser Unterscheidungen für die Rechtstheorie, die Rechtsgeschichte oder die politische Wissenschaft zu diskutieren. Doch vom Gesichtspunkt der Demokratie, verstanden als offene Entwicklung der Bestimmung politischer Subjektivität, sind alle diese nacheinander erworbenen Rechte politische Rechte. 
Politisch aufgrund ihres Ursprungs (errungen durch Kämpfe), politisch aber vor allem aufgrund ihrer anthropologischen Tragweite: Sie sind die Attribute eines werdenden Subjekts, das sich der Stabilität festgelegter, erstarrter Identitäten entledigt hat. Bereits Kelsen hatte die Unterscheidung zwischen zivilen und politischen Rechten mit der Bemerkung ins Wanken gebracht, dass die subjektiven Privatrechte als politische Rechte insofern betrachtet werden können, als das Individuum an der Rechtserzeugung teilhat, indem es die Rechtsmaschinerie in Gang setzt, um eine Gerichtsentscheidung herbeizuführen; so wie es auch dadurch an der Rechtserzeugung teilhat, dass es die Mitglieder eines Gesetzgebungsorgans wählt. ${ }^{52}$ Umgekehrt könnte man sagen, dass in einem demokratischen Regierungssystem die politischen Rechte subjektive Privatrechte insoweit sind, als sie individuell innegehabt und ausgeübt werden, folglich, sind sie einmal gewährleistet, konstitutiv für das Subjekt sind, das ein Individuum bleibt. Mit anderen Worten: Es gibt keinen Grund, die politischen Rechte als kontingente Attribute des modernen Subjekts (der Person) anzusehen. Wenn die Identität des Subjekts nicht von Natur aus gegeben ist, sich vielmehr in der Geschichte der Einrichtung/Anerkennung von Rechten ausgebildet hat, sind die politischen Rechte nicht minder kontingente Attribute als die bürgerlichen Rechte. Gleiches gilt, muss es wirklich gesagt werden, für die sozialen Rechte: Die Unterscheidung zwischen Freiheitsrechten und persönlichen Rechten ist nur dann sinnvoll, wenn davon ausgegangen wird, dass erstere Attribute anerkennen, die das menschlichen Individuum von Natur aus innehat, während die zweiten ihm vom Staat gewährt werden..$^{33}$

\section{Subjektive Rechte und Globalisierung}

Was wird aus dem derart mit dem Rechtssubjekt gleichgesetzten politischen Subjekt, wenn der Staat das Monopol auf die Rechtsgarantie verliert? Hier gilt es, die zu Anfang des zweiten Kapitels begonnenen Überlegungen weiterzutreiben und auf Webers Charakterisierung der subjektiven Rechte zurückzukommen. Wenn Weber auf "außerstaatliches" Recht zu sprechen kommt, das durch andere als physische Zwangsmittel garantiert wird, bezieht er sich nicht nur auf hierokratische Gewalt, also die Exkommunion, er erwähnt auch die

"Androhung eines Ausschlusses aus einem Verband, eines Boykotts oder ähnlicher Mittel, und ebenso das Inaussichtstellen diesseitiger magisch bedingter Vorteile oder Unannehmlichkeiten oder jenseitiger Belohnungen oder Strafen für den Fall eines bestimmten Verhaltens « ${ }^{54}$

Magie und jenseitige Belohnungen verweisen auf archaische Gesellungsformen, die uns hier nicht interessieren; die Erwähnung des Boykotts hingegen legt nahe, dass die Rechtsgarantie nicht nur von anderen politischen Mächten als dem modernen Staat abhängen kann, sondern gegebenenfalls auch auf Zwangsmaßregeln von Seiten privater Körperschaften beruht. Weber verweist auf schwarze Listen von Kreditorenund Hausbesitzerverbänden und die damit einhergehenden Boykottmaßnahmen, wobei er auch in diesem Zusammenhang vermerkt:

»Und natürlich kann sich dieser Zwang auch auf staatlich gar nicht garantierte Ansprüche erstrecken: dann sind diese trotzdem subjektive Rechte, nur mit[tels] anderer Gewalten. ${ }^{55}$

Diese Bemerkung gewinnt heute eine Tragweite, die Weber nicht vorhersehen konnte in einer Epoche also, in der wir einer Vervielfachung und Diversifizierung 
normenerzeugender Instanzen beiwohnen, die zum Großteil sich der Kontrolle der Nationalstaaten entziehen und neben privaten Einrichtungen wie Nichtregierungsorganisationen (NGO) auch multinationale Unternehmen einschließen. Auch wenn der Staat noch lange nicht von der politischen Weltbühne abgetreten ist Juristen, Historiker und Politologen sind sich darin einig, dass er das Monopol auf Rechtserzeugung verloren hat. ${ }^{56}$ Aus der Fülle an Literatur, die die Aushöhlung des staatlichen Rechtsmonopols dokumentiert, soll hier nur Mireille Delmas-Martys Beschreibung der "großen Rechtskomplexität der Welt « ${ }^{57}$ Erwähnung finden, eine Situation, die, wie sie selbst hofft, nur übergangsweise herrscht und in eine neue Normenhierarchie münden sollte, die zwar flexibler wäre als die staatlich geprägte, aber dem internationalen Recht den Charakter einer Rechtsordnung zurückgeben könnte. Zurückhaltender und wahrscheinlich realistischer fällt die Diagnose von Julie Allard und Antoine Garapon aus, die das Phänomen unter der Perspektive des »Kommerzes der Richter" analysieren, d.h. der grenzüberschreitenden Austauschbeziehungen von Richtern untereinander. Allard und Garapon rufen dazu auf, »die Vorstellung einer irgendwie gearteten Rechtsordnung zu Grabe zu tragen«, und beschränken ihre Hoffnungen auf die Herausbildung einer neuen »Form von weltweiter Rechtsbühne«, von der sie glauben möchten, dass sie noch so etwas wie ein "soziales Band« enthält, ohne "dass dieses jedoch an eine Normenpyramide oder an eine bestimmte politische Ordnung geknüpft wäre.$^{58}$

Das mit der territorialen Fixierung der Macht verbundene staatliche Monopol auf Rechtsgarantie, worin Weber ein Ausnahmephänomen auf der Ebene der vergleichenden Geschichte der Zivilisationen gesehen hat, dürfte eine bloße Episode in der Geschichte des Okzidents gewesen sein. Wenn der weltweite Rechtsraum nicht mehr viel mit dem zu tun hat, was Kelsen eine »Rechtsordnung " nannte, dann bedeutet dies auch, dass der Rahmen politischen Handelns sich nicht mehr mit dem deckt, der in den großen Werken der modernen politischen Philosophie vorausgesetzt war. Um der Wirklichkeit der zeitgenössischen Politik gerecht zu werden, müssen in deren Konzept nicht nur die außerlegalen Manifestationen von Kritik und Protest eingehen, wie es kritische Denker ebenso fordern wie in jüngerer Zeit ein eher klassischer Autor wie Pierre Rosanvallon ${ }^{59}$, sondern es muss auch die dezentrale Stellung des Staates in der zeitgenössischen Topologie des Politischen berücksichtigt werden. Die Rechte, die Bedingungen ihres Erwerbs und ihrer Gewährleistung in das Zentrum der Interpretation des Politischen zu stellen heißt auch, darin Claude Lefort folgend, anzuerkennen, dass die zentrale Frage der Politik nicht die Aneignung der Macht sein darf. ${ }^{60}$ Doch anders als dieser noch zu einer Epoche glauben konnte, als die Reflexionen zur Politik sich auf die Verbindungen zwischen Totalitarismus und Demokratie konzentrierten, ist der Ort der Macht heute nicht mehr ein leerer Ort, vielmehr gleichsam zum Bersten gefüllt, geradezu überlaufen von vielfältigen und vielartigen Organismen, mit denen das politische Subjekt von nun an die Gewährleistung und Verteidigung seiner Rechte aushandeln muss. Die neue Pluralisierung der Machtinstanzen ermöglicht uns, die Geschichte der Moderne als die eines politischen Kampfes neu zu lesen, in dem es um die Bestimmung der Rechte eines zugleich rechtlichen und politischen Subjekts ging. Die Ausübung der klassischen politischen Mittel (Wahlrecht) war und ist eines der Mittel dieses Kampfes, im Rahmen des Nationalstaates wie übernationaler Einheiten, die bis zu einem gewissen Grad die Formen des Nationalstaates nachahmen (z.B. die Europäische Gemeinschaft); aber es ist selbstverständlich nur ein Mittel unter anderen. Auf transnationaler Ebene, auf der 
sich heute ein nicht unerheblicher Teil dieser Kämpfe abspielt, sind bei weitem nicht alle Machtinstanzen, mit denen die Individuen konfrontiert sind und von denen die mögliche Gewährleistung der von ihnen eingeklagten Rechte abhängt, der Kontrolle durch periodische Wahlen unterworfen. Umso wichtiger ist es anzuerkennen, dass die Mittel des politischen Handelns sich nicht auf die Wahl des Führungspersonals beschränken dürfen.

Sollten wir es wagen und an dieser Stelle von "Kosmopolitismus« bzw. Weltbürgerlichkeit sprechen? Dazu muss erst nochmals ernsthaft der Terminus überdacht werden. Denn in der Nachfolge von Kant ist die Internationalisierung des Rechts als ein Horizont der Universalität erträumt worden, die den modernen politischen »Menschen« von seiner letzten Partikularität befreien würde, der des Bürgers eines Nationalstaates. In diesem Sinne kann der Kosmopolitismus oder, wie es der deutsche Begriff so klar ausdrückt, die Weltbürgerlichkeit, als Bürgerschaft auf Weltebene interpretiert werden. Genau das tat namentlich Habermas Anfang der 90er Jahre, als er davon ausging, dass die fortschreitende Aushöhlung der Souveränität der Nationalstaaten einhergeht mit dem Aufbau supranationaler Instanzen, für die der Nationalstaat, »jene historische Gestalt, die wir zu überwinden im Begriffe sind«, dennoch als Modell und Wegweiser dienen kann. "Staatsbürgerschaft und Weltbürgerschaft bilden ein Kontinuum, das sich immerhin schon in Umrissen abzeichnet. « ${ }^{61}$ Der gegenwärtige Zustand der Globalisierung des Rechts lässt daran zweifeln, dass diese einen solchen Weg einschlägt. Akzeptiert werden muss die radikale Ambiguität, die diese Globalisierung vom Gesichtspunkt einer Geschichte der Menschheit darbietet, die sich nach dem Beispiel der Hegelschen Geschichtsphilosophie als Geschichte des Universellen schreiben würde; nicht minder zwingend ist, sich zu fragen, worin die Zukunft des modernen politischen Subjekts besteht, wenn der Staat, der es schuf, indem er allen anderen Gemeinschaftszugehörigkeiten als der (Staats-)Bürgerschaft ihre politische Bedeutung entzog, nur mehr als eine Machtinstanz unter anderen figurieren wird.

In gewisser Weise könnte es so erscheinen, als würde mit dem Aufbau supranationaler Rechts- und Gerichtsinstanzen die Abschaffung rechtsspezifischer Unterschiede vollendet und damit die der Staatssouveränität zutiefst innewohnende Aporie in der Weise behoben, in der Alexander mit dem gordischen Knoten verfuhr. Diese von Hobbes bemerkenswert in Szene gesetzte Aporie beruht darin, dass die Abschaffung statutarischer Unterschiede einherging mit der Entgrenzung der souveränen Macht. Das von ständischen Identitäten befreite Individuum fand sich nun auch der Ressourcen beraubt, die die Stände ihm einst boten, um sich gegen die Herrschaft der Fürsten zu wehren. Die Unterwerfung des Subjekts unter den Staat bildet die dunkle Kehrseite der Unabhängigkeit des modernen politischen Subjekts von den Gemeinschaftsbindungen, weshalb auch die modernen Naturrechtstheorien auf vielfältige Weise versucht haben, ein wie immer minimales Widerstandsrecht gegenüber der Allmacht des Staates zu rechtfertigen. Supranationale Gerichte wie der Europäische Gerichtshof für Menschenrechte oder der Internationale Strafgerichtshof unterminieren diese Allmacht, indem sie eine heteronome Begrenzung der Macht des Staates ermöglichen, was auf den ersten Blick überzeugender wirkt als die Selbstbeschränkung, mit der die Theoretiker des Rechtsstaats sich begnügen mussten. Es wäre allerdings falsch, daraus $\mathrm{zu}$ schließen, die Beziehungen zwischen Machtinstanzen und Rechten hätten damit ihren problematischen Charakter verloren; 
dieser verschiebt sich nur und nimmt andere Formen an. Können die Beispiele des Europäischen Gerichtshofs für Menschenrechte oder des Internationalen Strafgerichtshofs noch nach dem Muster einer (wenngleich minder strikt als im staatlichen Rahmen geltenden) »Hierarchie des Rechts« interpretiert werden, so gemahnt die allgemeine Lage des weltweiten Rechts eher an Anarchie, d.h., einer Formulierung Mireille Delmas-Martys zufolge ${ }^{62}$, an einen "Rechte-Markt«, in dem es zumindest manchen Akteuren frei steht, die ihnen im jeweiligen Fall am günstigsten erscheinende Jurisdiktion zu wählen. Die Möglichkeit des Wählens und die jeweilige Autorität der Jurisdiktion hängt von Kräfteverhältnissen ab, deren Voraussetzungen wiederum außerrechtlicher Natur sind, so etwa die ungleiche Stärke der Staaten, Wirtschaftsgruppen oder internationalen Organismen aller Art. Dass diese Wahlmöglichkeit für den Großteil der Individuen noch virtuell ist, hindert nicht, dass sie die Universalität des Rechts jetzt bereits beeinträchtigt. Die Globalisierung des Rechts befreit (tendenziell) das moderne politische Subjekt von jenem Rest an statutarischer Zugehörigkeit, der nationalen Staatsbürgerschaft, lediglich, um es neuen Partikularismen auszuliefern, nämlich Interessen, die die Heterogenität der rechtlichen oder quasi-rechtlichen Normensysteme strategisch auszunutzen in der Lage sind.

Wenn es einen Gegenstand gibt, der sich der Aufmerksamkeit aller dem Recht sich widmenden Disziplinen anempfiehlt, dann ist es genau diese neue und ursprüngliche Konfiguration der Beziehungen zwischen Machtinstanzen und Recht. Konnte der Staat noch als Annäherung an das Universelle gelten und dementsprechend eine ethische Alternative zu den transzendenten Rechtfertigungen des Rechts früherer Epochen darstellen (was Hegel bewog, den Staat als »Wirklichkeit der sittlichen Idee« zu kennzeichnen ${ }^{63}$, ist mit der Vielfalt der vom zeitgenössischen Rechtspluralismus gebotenen Mittel die Gefahr gegeben, die symbolische Verklärung abzuschaffen, die die Gestalt des sgleichen Rechts für aller den Interessen auferlegt. Sie führte damit jenen Prozess zu Ende, den Weber in einem anderen Kontext vorhergesagt hatte: die Interpretation des Rechts als »eines rationalen, daher jederzeit zweckrational umzuschaffenden, jeder inhaltlichen Heiligkeit entbehrenden, technischen Apparats $\ll{ }^{64}$ Sofern nicht erneut in irgendeiner Form ein Analogon zur politischen Schicksalsgemeinschaft aufkommt, lässt sich die Zukunft der Demokratie nur schwer anders denn als Bestätigung und Erweiterung der den Individuen garantierten Rechte denken. Dem Staat ist die Erzeugung des modernen politischen Subjekts zu verdanken, dessen Identität nicht in der Teilhabe an der Macht liegt, sondern im Recht, Rechte zu haben. Diese geschichtlich gewachsene Figur des politischen Subjekts bleibt der Bezugspunkt jeder demokratischen Praxis, während zugleich das Rechtsmonopol des Staates, das seine Entwicklung ermöglichte, zerfällt. Die Schwierigkeit heute beruht darin, sich auszumalen, wie dieser Rechtsanspruch auf Rechte, der als politisches Recht schlechthin betrachtet werden muss insofern, als er die Voraussetzung für den Erwerb und den Erhalt jedes bestimmten Rechts darstellt, sich die durch die Diversifizierung des Rechtsraums eröffneten Gelegenheiten zunutze machen kann, ohne zu jener letzthinnigen Desakralisierung des Rechts beizutragen: seiner Verkürzung auf eine bloße Technik der öffentlichen wie privaten Machtinstanzen, deren chaotisches Nebeneinander die Wirklichkeit unseres politischen Universums ausmacht. 


\section{BIBLIOGRAPHIE}

Allard, J. / Garapon, A. (2005): Les juges dans la mondialisation, Paris, Seuil (= La République des Idées).

Anter, A. (1995): Max Webers Theorie des modernen Staates, Berlin, Duncker \& Humblot.

Balibar, E. (2002): Droit de cité, Paris, PUF.

Benhabib, S. (2008 [2004]): Die Rechte der Anderen. Ausländer, Migranten, Bürger. Aus dem Amerikanischen von Frank Jakubzik, Frankfurt a.M., Suhrkamp.

Bobbio, N. (1998): Essais de théorie du droit, Paris, Bruylant / L.G.D.J.

Colliot-Thélène, C. (1998): »L'ignorance du peuple«, in: Duprat, G. (Hg.): L’ignorance du peuple, Paris, PUF, S. 17-40.

Colliot-Thélène, C. (2005): "La fin du monopole de la violence légitime?«, in: Coutu M. / Rocher, G. (Hg.): La légitimité de l'État et du droit. Autour de Max Weber, Québec, Presses de l'Université Laval, S. 24-46 (Erstveröffentlichung in: Revue d'Études Comparatives Est-Ouest, 2003, Bd. 34 (1), S. 5-31).

Colliot-Thélène, C. (2006): »Après la souveraineté: que reste-t-il des droits subjectifs?«, aufrufbar im Internet unter: www.cceae.umontreal.

Colliot-Thélène, C. / Kervégan J.F. (2002): De la société à la sociologie, Paris, ENS Editions (= collect. Theoria).

Constant, B. (1997 [1819]): »De la liberté des Anciens comparée à celle des Modernes«, in: ders.: Écrits politiques, Paris, Gallimard.

Delmas-Marty, M. (2006): Le pluralisme ordonné, Paris, Seuil.

Descombes, V. (2004): Le complément de sujet, Paris, Gallimard.

Duguit, L. (2003): L'État, le droit objectif et les lois positives, Paris, Dalloz.

Foucault, M. (1999 [1997]): In Verteidigung der Gesellschaft. Vorlesungen am Collège de France (1975-76). Aus dem Französischen von Michaela Ott, Frankfurt a.M., Suhrkamp.

Foucault, M. (2004): Geschichte der Gouvernementalität II: Die Geburt der Biopolitik. Aus dem Französischen von Jürgen Schröder, Frankfurt a.M., Suhrkamp.

Habermas, J. (1992): „Staatsbürgerschaft und nationale Identität «, in: ders.: Faktizität und Geltung. Beiträge zur Diskurstheorie des Rechts und des demokratischen Rechtsstaats, Frankfurt a.M., Suhrkamp, S. $632-660$

Habermas, J. (1996a): »Der europäische Nationalstaat - Zur Vergangenheit und Zukunft von Souveränität und Staatsbürgerschaft«, in: ders.: Die Einbeziehung des Anderen. Studien zur politischen Theorie, Frankfurt a.M., Suhrkamp, S. 128-153.

Habermas, J. (1996b): »Über den internen Zusammenhang von Rechtsstaat und Demokratie«, in: ders.: Die Einbeziehung des Anderen. Studien zur politischen Theorie, Frankfurt a.M., Suhrkamp, S. 293-305.

Hayek, F.A. (1981): Recht, Gesetzgebung und Freiheit, Bd. 2: Die Illusion der sozialen Gerechtigkeit. Aus dem Amerikanischen übertragen von Martin Suhr, Landsberg am Lech, Verlag moderne Industrie Wolfgang Dummer \& Co. 
Hegel, G.W.F. (1970 [1821]): Grundlinien der Philosophie des Rechts oder Naturrecht und Staatswissenschaft im Grundrisse. Frankfurt a.M., Suhrkamp (= Theorie Werkausgabe, 7).

Hegel, G.W.F. (1998): Principes de la philosophie du droit, Paris, PUF.

Hobbes, T. (1984 [1671]): Leviathan oder Stoff, Form und Gewalt eines kirchlichen und bürgerlichen Staates. Übersetzt von Walter Euchner, Frankfurt a.M., Suhrkamp.

Jellinek, G. (1959 [1900]): Allgemeine Staatslehre, 3. Aufl., 6. Neudruck, Darmstadt, Wissenschaftliche Buchgesellschaft.

Jouanjan, O. (Hg.) (2001): Figures de l'État de droit, Straßburg, Presses Universitaires de Strasbourg. Jouanjan, O. (2004): „Les fondations de la théorie des droits subjectifs dans la pensée de Georg Jellinek«, in: Revue universelle des droits de l'homme, 3, S. 6-16.

Jouanjan, O. (2005): Une Histoire de la Pensée juridique en Allemagne, Paris, PUF.

Kelsen, H. (1976): Reine Rechtslehre, unveränderter Neudruck der 2., vollst. neu bearb. u. erw. Aufl. 1960, Wien, Deuticke.

Kelsen, H. (1979): Allgemeine Theorie der Normen, Wien, Manz.

Kelsen, H. (1981): Vom Wesen und Wert der Demokratie, 2. Neudruck der 2. Aufl. Tübingen 1929, Aalen, Scientia Verlag.

Lefort, C. (1981): L'invention démocratique, Paris, Fayard.

Lefort, C. (2007): Le temps présent. Écrits 1945-2005, Paris, Belin.

Lochak, D. (2005): Les droits de l'homme, Paris, La Découverte.

Rancière, J. (2004): Aux bords du politique, Paris, Gallimard.

Rancière, J. (2005): La haine de la démocratie, Paris, La Fabrique éditions.

Rancière, J. (2008 [2000]): Zehn Thesen zur Politik. Aus dem Französischen von Marc Blankenburg, Zürich-Berlin, Diaphanes.

Rawls, J. (2002 [1999]): Das Recht der Völker. Übersetzt von Wilfried Hinsch, Berlin / New York, de Gruyter.

Rosanvallon, P. (2006): La contre-démocratie, Paris, Seuil.

Runciman, D. (1997): Pluralism and the Personality of the State, Cambridge, Cambridge University Press.

Teubner, G. (1996a): »Globale Bukowina. Zur Emergenz eines transnationalen Rechtspluralismus«, in: Rechtshistorisches Journal, 15, S. 255-290.

Teubner, G. (1996b): Global Law without a State, Aldershot, Dartmouth.

Villey, M. (1983): Le droit et les droits de l'homme, Paris, PUF.

Villey, M. (2003): La formation de la pensée juridique moderne, Paris, PUF.

Weber, M. (1964 [1921]): Wirtschaft und Gesellschaft. Grundriß der verstehenden Soziologie, Studienausgabe, Köln / Berlin, Kiepenheuer \& Witsch.

\section{NOTES}

1. Vgl. insbesondere Teubner (1996a, 1996b); Delmas-Marty (2006); Allard / Garapon (2005). 
2. Rawls (2002).

3. Benhabib (2008).

4. Was die Juristen angeht, vgl. weiter unten (2). Von Seiten der Philosophen, vgl. Descombes (2004), der den "Streit um die subjektiven Rechte« unter Bezug insbesondere auf Michel Villey neu aufleben lässt. Descombes sieht im Rechtssubjekt einen Ausdruck der Metaphysik der Subjektivität, die er mit einer von Wittgenstein inspirierten "grammatikalischen" Argumentation aufzulösen sucht.

5. Hegels 1821 erschienenes Hauptwerk stellt sich dar als eine Philosophie des Rechts (Grundlinien der Philosophie des Rechts) und trägt als Untertitel »Naturrecht und Staatswissenschaft im Grundrisse«. Zur Interpretation des in diesem Untertitel herangezogenen Rechtsbegriffs beziehen wir uns auf die Einführung Jean-François Kervégans zu seiner neuen Übersetzung dieses klassischen Werks (1998, S. 21 ff.).

6. Hayek (1981).

7. Zum Umgang der Juristen mit dem Begriff des Rechtsstaats siehe das von Olivier Jouanjan (2001) herausgegebene Sammelwerk, insbesondere seine Einleitung (S. 7-52). Lesenswert auch der Beitrag Jean-François Kervégans (S.101-123), der zeigt, dass der Begriffsrahmen der Theorien des Rechtsstaats bereits bei Kant, Fichte und Hegel vorweggenommen wird. Hinsichtlich der Vorläufer der Soziologie, vgl. Colliot-Thélène / Kervégan (2002).

8. Dies gilt z.B. für Habermas (1996b).

9. Zu einer weitergehenden Analyse dieses Punkts, vgl. Colliot-Thélène (1998).

10. Constant (1997), S. 595.

11. Habermas bildet hier eine Ausnahme. Seit der Schrift Faktizität und Geltung (1992), die einen Wendepunkt in seinem Denken darstellt, und um seine Position von der der Vertreter des Republikanismus abzusetzen, bei denen er eine kommunitaristische Interpretation des konstitutiven Konsens des politischen Willens argwöhnt, hat er dem Recht eine essentielle Rolle für das Funktionieren der demokratischen Institutionen zugewiesen.

12. Vgl. Lefort (2007), S. 366: "Demokratie ist in meinen Augen etwas anderes als ein Ensemble von historisch entwickelten Institutionen oder, im engeren Sinn des Wortes, ein spezifisches Regierungssystem«; Rancière (2008), S. 19, »Zehn Thesen zur Politik«, These 4: »Demokratie ist keine politische Herrschaftsform«.

13. Foucault (1999), S. 33.

14. Foucault (2004), S. 375-377.

15. Foucault (1999), S. 34: Die an der Frage der Legitimität der Macht ausgerichtete Theorie des Rechts ist »letztlich Verdrängung der tatsächlichen Herrschaft und ihrer Folgen«; »der Diskurs und die Technik des Rechts (hatten) im Wesentlichen die Funktion, den Faktor Herrschaft innerhalb der Macht zum Verschwinden zu bringen«.

16. Ich selbst habe auf diese Kritik in einem Beitrag auf einem Kolloquium im September 2006 in Montreal zurückgegriffen (Colliot-Thélène [2006]).

17. Vgl. Lefort $(1981,2007)$.

18. Colliot-Thélène $(2005,2006)$.

19. Weber (1964), S. 25.

20. Ebd., S. 237.

21. Ebd.

22. Weber (1964), S. 533.

23. Ich ziehe es vor, von Individuierung zu sprechen statt von Individualisierung, um so die Verwechslung mit dem juristischen Begriff der Individualisierung zu verhindern, der (zumindest bei Kelsen) bei der rechtlichen Entscheidung die Anwendung eines allgemeines Gesetzes auf einen Einzelfall bezeichnet.

24. Als Theoretiker der absoluten Macht kann Hobbes schwerlich als Liberaler gelten. Doch ist es einigen seiner Leser nicht entgangen, dass das individualistisches Fundament, auf das er die 
Souveränität des Staates gründet, in diesen Absolutismus einen Riss herbeiführt, aus dem das liberale Denken nur zu leicht Nutzen ziehen konnte.

25. Hobbes (1984), S. 173-184. Ich danke Etienne Balibar, meine Aufmerksamkeit auf dieses Kapitel gelenkt zu haben, wie auch dafür, mich auf das Werk von David Runciman hingewiesen zu haben, Pluralism and the personality of the State (1997). Darin wird untersucht, wie nach dem Tod Hobbes' die Rechtsfähigkeit der dem Staat unterstehenden Vereinigungen behandelt wurde - ein Punkt, dem ich im begrenzten Rahmen dieses Artikel nicht weiter nachgehen kann, aber auf den natürlich zurückgekommen werden muss.

26. Hobbes (1984), S. 178.

27. Foucault (2004), S. 377.

28. Villey $(1983,2003)$.

29. Duguit (2003), S. 141.

30. Ebd., S. 227.

31. Um gegebenenfalls meine allzu knappen Analysen der Position Jellineks zu präzisieren oder zu korrigieren, sei der Leser auf die Arbeiten Olivier Jouanjans verwiesen, insbesondere Jouanjan (2004), S. 6-16, sowie, in einer allgemeineren Perspektive, auf das Jellinek gewidmete Kapitel seines kürzlich veröffentlichten Opus magnum, Une Histoire de la Pensée Juridique en Allemagne (1800-1918) (Jouanjan [2005]).

32. Duguit (2003), S. 128.

33. Jellinek (1959), S. 366 f. Andreas Anter hat nachgewiesen, dass Webers Definition des Staates anhand des Monopols an legitimer Gewalt nur die soziologisch zweckmäßige Übertragung einer These war, die von zahlreichen deutschen Juristen seiner Epoche akzeptiert wurde, eben auch Jellinek. Von diesem zitiert er eine andere, der von Duguit nahestehende Passage ebenfalls aus der Allgemeinen Staatslehre, ebd., S. 256: „Die Entwicklung des Staates ist aber überall von einem Aufsaugungsprozeß der selbständigen Rechtsbildung und des Rechtsschutzes in sämtlichen ihm untergeordneten Verbänden begleitet, so daß schließlich der Staat allein als Quell planmäßiger Fortbildung des Rechtes erscheint. Heute ist alle planmäßige [...] Rechtsbildung entweder vom Staate selbst ausgeübt oder übertragen oder zugelassen [...]«; vgl. Anter (1995).

34. Dazu vgl. Bobbio (1998), S. 248.

35. Kelsen (1976), S. 225.

36. Ebd.

37. Ebd., S. 130.

38. Kelsen (1979), Kap. 33, S. 110 f. sowie die Anmerkungen 85, 86 und 87 (S. 269-271).

39. Ebd., S. 269.

40. Kelsen (1976), S. 135. Die gleiche These in Kelsen (1979), S. 110: »Aber dieses Recht >im subjektiven Sinner ist nicht etwas von dem Recht im objektiven Sinne, der Rechts-Norm, Verschiedenes [...] «.

41. Kelsen (1976), S. 134. Die Vorstellung, das Subjekt könne über ein Recht wie über ein Hab und Gut verfügen, in anderen Worten, die Vorstellung eines Rechtsbesitzes, ist Kelsen zufolge an die Rechtfertigung des Privatbesitzes gebunden; aus diesem Grund prangert er diese Vorstellung denn auch als ideologisch an.

42. Vgl. Kelsen (1976), S. 173.

43. Ebd.

44. Vgl. ebd., S. 139, und Bobbio (1998), S. 239.

45. Vgl. N. Bobbio: »Kelsen et les sources du droit«, in: Bobbio (1998), S. 227-236.

46. Kelsen (1976), S. 174. Von mir hervorgehoben, CCT.

47. Vgl. Kelsen (1976), S. 283 ff.; ebenfalls Kelsen (1981).

48. Gegenstand und Umfang des vorliegenden Artikels erlauben mir nicht, näher auf die Natur des demos der in Begriffen der subjektiven Rechte neu interpretierten Demokratie einzugehen; jener ist weder eine homogene Einheit noch bloße Summierung von Einzelnen. Ich beschränke 
mich hier auf die Feststellung, dass die (individuelle und gerade dadurch potenziell universelle) Form, in der die Rechte zum Ausdruck kommen, keineswegs eine atomistische Auffassung von der Realität des sozialen Körpers impliziert.

49. Ich denke, hier mit der Position in Einklang zu stehen, die Etienne Balibar (2002, S. 10) zum Ausdruck bringt, wenn er anhand des für meine Ausführungen exemplarischen Falls von zivilem Ungehorsam sich nicht der These anschließt, wonach »Ungehorsam gegenüber der Autorität des Staates, die Weigerung, Gesetze auszuführen, deren Inhalt und Zustandekommen anfechtbar erscheinen, das Wesen der aktiven (Staats-)Bürgerschaft, der citoyenneté, bilden. Der Individualismus des `Bürgers wider die Machtinstanzen`stellt ebenso wenig eine Politik dar wie der Anarchismus des >Absterbens des Staates« ein Gemeinwesen stiftet." Wobei er freilich hinzufügt, dass "Staatsbürgerschaft und Gemeinwesen« (ich würde Demokratie sagen) »ohne diesen notwendigen Bezug zum Ungehorsam und sogar ohne den periodischen, tatsächlichen Rückgriff auf dieses Risiko nicht existieren können«.

50. Rancière (2005), S. 82.

51. Ebd.

52. Kelsen (1976), S. $143 \mathrm{f}$.

53. Es erscheint mir triftiger, mit Danièle Lochak (2005) von Rechten erster, zweiter und dritter Generation zu sprechen.

54. Weber (1964), S. 237.

55. Ebd., S. 238.

56. Vgl. Teubner (1996a, 1996b).

57. Delmas-Marty (2006), S. 27.

58. Allard / Garapon (2005), S. 24 f.

59. Vgl. Rosanvallon (2006).

60. Vgl. Lefort (2007), S. 561.

61. Habermas (1996b), S. 130; (1996a), S. 660.

62. Delmas-Marty (2006), S. 23.

63. Hegel (1970), S. 398.

64. Weber (1964), S. 656.

INDEX

Schlüsselwörter : Demokratie, politischer Kampf, Rechte (subjektive), Rechtssubjekt, Weltbürgerschaft

Mots-clés : citoyenneté mondiale, démocratie, droits subjectifs, lutte politique, sujet de droit

\section{AUTEURS}

\section{CATHERINE COLLIOT-THÉLÈNE}

Catherine Colliot-Thélène ist Professorin für Philosophie an der Universität Rennes I. Nährere Informationen finden Sie hier. 